\title{
BEYOND CRIMINAL LAW: THE MULTIPLE CONSTITUTION OF ADDICTION IN AUSTRALIAN LEGISLATION
}

\section{KATE SEEAR \& SUZANNE FRASER}

\section{INTRODUCTION}

The term 'addiction' has 'become popular in academic and everyday discourse', used to describe a range of activities including alcohol and other drug (AOD) consumption, eating, sex, work, exercise, gambling, shopping and the use of the Internet (Karasaki, Fraser, Moore and Dietze 2013: 195). According to Robin Room, the language of addiction and the concepts that underpin it 'have been extended to cover an ever wider range of behaviours and states' (2006: 285). Addiction terminology can also be found in a range of other areas, including science and medicine, public policy, the law, the arts, self-help literature, media and other forms of popular culture. Despite the widespread use of the language of addiction, however, little consensus exists about its key features. Karasaki et al. (2013) have argued that addiction remains a largely 'ambiguous concept'. In their study of AOD policy and service provision, they found 'differing, competing or incompatible philosophies of addiction' at play (Karasaki et al. 2013: 195-196). The word 'addiction' comes from the Latin term addicere, which signals the relationship between masters and slaves in Roman law (Seddon 2007a, Fraser and valentine, 2008). In this sense, the idea of attenuated will or lack of volition is foundational to the concept of addiction (West 2001). Importantly, however, even the notion of volition is configured differently across addiction research, policy and practice (Karasaki et al. 2013, Keane 2002). Are addicts slaves to their addiction, having little or no capacity to control their behaviour? If so, why do some people have less trouble changing their behaviour than others (Keane 2002)? Where claims are made about an absence of capacity or free will, does this pertain only to the substances or activities identified as the source of the addicts' problems, or does it also extend to other aspects of their conduct? How, in short, is the agency of the addict understood? 
These are important questions, not the least because how we enact addiction has implications for many areas of health, legal and other policy. How, for example, should we diagnose addiction? How should we manage and treat it? Indeed, managing and treating addiction presupposes a particular definition of it. How should we respond to criminal activity seen as linked to addiction, such as drink driving or illicit drug possession? In all these contexts, the absence of consensus matters. There is evidence, for example, that differences and inconsistencies in approaches between service providers can undermine individuals' treatment progress (Burke and Clapp 1997, Taxman and Bouffard 2003, Treloar and Holt 2006). Further, the deployment of addiction terminology and related concepts of volition, rationality and autonomy can have major ramifications for those people labelled 'addicts'. ${ }^{1}$ Understanding individual behaviour through the prism of addiction is a relatively recent historical phenomenon (Levine 1978, Room 2003) and partly the product of a desire to develop less stigmatising accounts of behaviour (originally heavy drinking) than traditional designations of moral failing (Seear and Fraser 2010a, 2010b). According to Fox (1999: 215), the 'disease' model of addiction - in which addiction figures as a disorder or sickness - is assumed by some to be progressive insofar as it positions AOD-related illegal or antisocial conduct as a manifestation of illness, thus relieving 'drug-dependent persons of responsibility for their condition'. This assumption has been the subject of extensive critique, however, with some scholars (e.g. Brook and Stringer 2005) arguing that the stigmatisation and marginalisation of those labelled addicts persists under the disease model in that the 'addict' comes to be constituted as sick and in need of intervention. Other models or concepts of addiction may also produce and reproduce stigma, insofar as ideas about agency vary. Within the Alcoholics Anonymous (AA) tradition, for example, 'an alcoholic who has not had a drink for twenty years nevertheless still suffers from the incurable disease of alcoholism' (Keane 2002: 2).

\footnotetext{
${ }^{1}$ We acknowledge at this point that questions about both volition and agency in this context are complex and complicated (especially insofar as different areas of the law may conceptualise legal capacity differently, using different tests and tools for assessment). It is beyond the scope of the present paper to address these issues in depth, although it is an area we aim to explore in future research.
} 
In this sense, the AA definition of the 'alcoholic' constitutes the affected individual as always and inherently sick, and - in that sickness is stigmatising and marginalising - may attach to the individual in perpetuity.

Approaches to addiction continue to change in response to social and political forces including scientific research and knowledge. Most recently, addiction has become the object of neuroscientific research, a field increasingly mobilised to understand all aspects of human subjectivity and behaviour. As Scott Vrecko (2010) has argued, neuroscience is creating new biological truths about the brain - about neurotransmitters and receptor sites for drugs, and about the nature of addiction and compulsion. While social and cultural factors are sometimes acknowledged within this field as contributing to addiction, the 'brain reward system' is the main focus of the new approach. According to neuroscience, the brain's reward system evolved in order to reinforce behaviours geared towards survival - sex and eating being primary examples (Hyman, 2005). These activities prompt the release of the neurotransmitter dopamine, producing sensations of pleasure. Addictive drugs are said to 'hijack' this reward system by binding to the same receptor sites in the brain and producing intense sensations of pleasure (Robinson and Berridge, 2003). As the brain adapts to the presence of a drug, its circuitry changes, further reinforcing the effects of the drug. According to scientists from the US National Institute on Drug Abuse (leading proponents of the neuroscience model) this is 'the neurobiology of behaviour gone awry' (Volkow and Li, 2004: 163). Lauded by some, the neuroscience model of addiction has also been met with scepticism among clinicians and researchers. As historian David Courtwright (2010) points out, its clinical influence has so far been limited, and it cannot be said to have alleviated, as neuroscientists promised, the stigmatisation of addicts. Despite these limitations, neuroscience continues to expand into the domain of addiction and compulsive behaviour, taking in so-called behavioural addictions and those that defy strict classification, such as overeating and obesity (Fraser, 2013), all the while remaking the meaning of the thinking 
subject, the relation between the mind and the body, and the nature of individual volition and agency.

For all of these reasons, it is vital that we attend to the processes by which addiction is defined, deployed, diagnosed, produced and managed across different settings (especially since some of these processes are less visible and publicly monitored than others - indeed some operate right at the margins of social and political scrutiny). Also vital is the consideration of some of the possible 'effects' of these processes, especially where there are inconsistencies within settings and across related settings. One broad area in which addiction holds a central place is the law. The role of the criminal law in the regulation of drugs and addiction is well known, and the subject of considerable academic interest and debate (e.g. Burns and Peyrot 2003, Clancey and Howard 2006, Wild 2006, Seddon 2007b, Fitzgerald 2008, Gowan and Whetstone 2012). Within the criminal law, AOD use, abuse, misuse, dependence and addiction feature prominently. ${ }^{2}$ Most obviously, all Australian states and territories prohibit the possession, use, production and dealing in a range of illicit substances. This mirrors practices in many other jurisdictions around the world, although the specific legislation, substances and options for sentencing differ, sometimes considerably. Substance use, abuse and 'addiction' also feature in the criminal law in less obvious ways, including, for example, as mitigating factors in pleas relating to other offences such as murder, rape and robbery, and offences against the person. In this sense, lawyers (and their expert witnesses) frequently participate in debates about different kinds of addictions, and the relationships between substance use, addiction, agency, subjectivity, responsibility, treatment and punishment. Alongside this, judges and other quasi-judicial figures are frequently enjoined to make decisions about the nature of these relationships, often with major implications for the

\footnotetext{
${ }^{2}$ For clarity's sake this article will use the expression 'addiction' to refer to the condition that is also at times called 'dependence' in legal documents, except where quoting those documents. While debate about the terminology rages in medical and psychological contexts such as in the negotiations surrounding the DSM-5 (Keane, Moore and Fraser 2011), the two terms are generally used interchangeably in legal settings, with variations depending on the prevailing medical terminology rather than on legal distinctions between the two.
} 
individuals concerned. The role of notions of addiction in criminal law beyond proceedings related directly to substance possession, use, production and dealing, receives little scholarly attention and analysis. Even more rarely considered are the many non-criminal legal contexts in which notions of addiction play a decisive part. It is to these many areas we devote the remainder of this article, our aim being to document a range of Australian non-criminal legal contexts in which notions of addiction are relevant to proceedings and outcomes. Thereafter, adopting a case study method taken from the work of science and technologies studies scholars Annemarie Mol and John Law (2002), we examine three specific pieces of legislation that bear upon addiction in some way. Our aim is to highlight their definitions and assumptions, and to consider the implications of inconsistencies and other weaknesses. In doing so, we raise questions about legal treatments of addiction also of relevance beyond Australia.

\section{BEYOND THE CRIMINAL LAW}

There are many ways in which the civil law grapples with questions of 'addiction'. These range from personal injury lawsuits pertaining to tobacco, pharmaceuticals and other consumables such as food, carbonated soft drinks and video games. Other quasi-judicial realms are also implicated in the regulation of addiction. Sporting tribunals, for example, deal with questions about licit and illicit drug use, and other administrative and executive bodies consider substance use, abuse and addiction in possible mitigation of other legal issues (e.g. traffic infringements and social security breaches). Despite the sometimes central place of addiction in these other legal realms, there has been a general tendency - with some exceptions (Gibson 2009, Kelly and Igelman 2009, Miller 2010, Flacks 2012, Race 2012) - to neglect them. As well, there have been few attempts to engage in comparative analyses of non-criminal contexts: an approach which can be productive for reasons that we will explain below. These oversights may be based on an assumption that the criminal law has the greatest potential to impact the lives of those labelled addicts, especially where criminal sanctions and/or mandatory treatment is at issue. Yet the way 
in which 'addiction' is understood, constituted and managed in these 'other' legal realms can have as much significance for the lives of those individuals as criminal sanctions. Much is at stake in this respect, especially when we consider that classifying someone as an 'addict' may have implications for their right to care for and work with children, other employment rights, their right to receive compensation, and more. It is vital, therefore, that we attend to how these various legal realms constitute addiction and the addict, and the possible implications of these practices.

Importantly, different legal realms are constituted in fundamentally distinct ways. Among other things, legal standards and proofs are different in civil and criminal law. So too are the legislative frameworks, available remedies, protocols for assessing drug use and addiction and the key decision-makers. The civil law has a unique set of concerns and remedies (to investigate the manifestation of injury and assign responsibility for it, for instance). Lawsuits pertaining to tobacco use and nicotine addiction (see below) necessarily demand consideration of the agency and responsibility of a range of subjects. The available tools, frameworks, and remedies differ markedly from those available through the criminal law, so that ideas about addiction, substances, agency and responsibility are necessarily characterised by complexity. In other words, the law enacts addiction as ontologically 'multiple', or, to use an expression drawn from the work of science studies theorist Annemarie Mol, as 'more than one [ontological reality] and less than many' (Mol 2002). For all of these reasons, we are likely to find considerable variation in the ways addiction is conceived and enacted in law. As Elizabeth Joh (2009: 175) has pointed out, although legal scholars, practitioners and politicians might talk about 'the response to an unwanted addictive behavior ... there is no unified social or legal response'. Joh goes on to argue that, 
Law and society respond to the problem of addictive behavior, and their responses in turn define and interpret the addict and addiction in question. Addiction characterizes the use of many substances, licit and illicit, and thus the characterization of the addict in these different settings suggests comparative discussion. (2009: 175; our emphasis)

The notion that the law has a constitutive effect (in, for example, producing the 'addict') both resonates with and departs from earlier work by the second author on the operation of concepts of addiction in official contexts, in this case policy and service provision within the state of Victoria, Australia (Moore and Fraser, 2013). Challenging conventional understandings of policymaking as a process by which social problems are simply identified and addressed, Moore and Fraser (2013) adopt a critical approach based on the work of French philosopher Gilles Deleuze (1994) and feminist theorist Paola Marrati (2006). Social problems such as addiction do not, they argue, exist prior to the policy-making process. Instead they are constituted within it. Indeed, addiction treatment policy and practice are fundamental elements in the process by which 'addiction' is constituted:

Our study findings suggest that alcohol and other drug treatment policy in Victoria does not merely identify and respond to a pre-existing condition called 'addiction'; instead, it is one of the processes through which addiction is produced. In other words, the problem of addiction emerges as an effect of treatment service provision rather than being the precursor to it. (Moore and Fraser 2013)

This approach can be contrasted with a conventional 'realist' perspective (Saldanha 2003) in which addiction is understood as a biological, natural or essential fact that pre-exists its identification and enactment in policy or practice. Similarly, the law can be understood as a realm within which addiction is constituted rather than simply reflected or addressed. In approaching 
the relationship between law and addiction in this way, we also draw upon the seminal work of Annemarie Mol, who argues that:

phenomena are always being made and remade [and that] multiple processes of constitution occur at any given time, shaped and informed by the various discourses in which they are inserted (or from which they emerge). (Fraser and Seear 2011: 12)

The nature, or ontology, of addiction as constituted in the law will also 'differ between sites' (Mol 2002: 43), such that the law generates 'different versions, different performances, different realities that co-exist in the present' (Mol 1999: 79).

Jennifer Murphy's research into the constitution and management of addiction within an American drug court $(2011,2012)$ offers a useful example here. Drug courts 'combine drug treatment with supervision by the criminal justice system' (2011: 258). Focusing on one court located in a large north-eastern city of the United States, Murphy's work explores 'how the court defines and manages drug addiction' (2011: 262). Using a multi-method approach including observations of court practice and interviews with program workers, Murphy explores how individuals are selected for the drug court, the basis upon which they are diverted into treatment programs and the model (or models) of addiction that are utilised by the court and those tasked with delivering treatment services. In conducting her analysis Murphy makes a number of useful observations about the operation of the drug court:

While the drug court program emphasised that its goal was to treat the problem of addiction, in reality a person's criminal record determined eligibility for the program more often than the criminal evaluation. (2011: 280) 
Murphy's point is that individuals were often diverted into the program regardless of how often they consumed drugs, which drugs they consumed or how they understood their relationship to drugs. Importantly, she found that people who consumed alcohol - as opposed to illicit drugs tended to be categorised as addicts less often. As well, individuals who sold drugs were often moved into a treatment program on the basis that they had an addiction, regardless of whether or not they actually consumed drugs. As Murphy also notes, 'several staff members of a treatment program affiliated with the drug court also revealed that they believed the majority of clients that the court sent to their treatment facility did not have significant drug problems' (2011: 281). Where people who sold - but did not consume - drugs were receiving treatment for a drug addiction, service providers managed this by suggesting that individual drug dealers had an addiction to money, or to the drug 'scene' or 'lifestyle'. Murphy concludes that 'each stage of the program involved an ambiguous notion of addiction' that virtually 'any problem could be placed' within (2011: 287-288). Although Murphy does not put it in quite these terms, her study is a useful example of the way that a set of legal practices and imperatives can converge to constitute both addiction and the addict. Whereas Murphy might be inclined to observe that the drug court produces an expanded notion of addiction and the addict, we would argue instead that the court performs addiction and the addict, that is, the drug court can be understood as doing more than simply identifying and managing a pre-existing problem or 'object': it actually produces it. Moreover, different drug courts can generate different and contrasting versions of addiction.

Moving beyond the criminal realm, Elizabeth Joh considers similar issues through a comparison of the characterisation of the addict in relation to two different substances: methamphetamine and tobacco. She argues that people who consume methamphetamine tend to be characterised consistently as 'debased' and 'deviant'. Understandings of smoking and smokers, on the other hand, have varied dramatically over the last 60 years. Smokers have been variously understood as 
rational decision-makers, victims of corporate negligence and a global cover-up of the risks associated with tobacco products, and - more recently - as choosing citizens whose smoking puts the health of others at risk. Joh argues that legal developments have both responded to and helped shape these shifting conceptualisations. So, for example, as evidence about the extent of corporate knowledge regarding the 'addictive properties of tobacco' emerged in civil litigation, understandings of 'addiction' changed. On the back of documents obtained through litigation, 46 states' attorney generals successfully sought compensation from tobacco companies. So, she argues,

The prevailing portrait of the smoker evolved from that of a voluntary decision maker to that of a victim harmed by an industry bent on deception. (2009: 188)

Joh concludes that social and legal responses to addiction 'can vary widely depending on the substance' and that responses can themselves 'vary over time' (2009: 191). She does not take these ideas further, but as with Murphy's work, we would argue again for a performativity analysis, this time focusing on the enactment of substances as much as the state of addiction. Legal responses and developments, that is, enact the substances in question, producing them as variously - harmful, risky and dangerous, or as possessed of certain 'addictive properties'. As these ideas are produced, reproduced and circulated, the potential for stigmatisation of certain individuals, groups, practices or entities may either grow or diminish.

\section{TRACING ADDICTIONS}

All these ideas can, we argue, be applied to an examination of the ways addiction figures in noncriminal settings across Australia. As we will see, addiction appears in a much wider range of legal areas than might ordinarily be appreciated, and much can be gained from comparative analyses of the law. We explore three specific pieces of Australian legislation in which the notion 
of AOD 'addiction' or 'dependence' figures. Our aim is to draw attention to how addiction is differentially defined in law, how it is established, by whom and through what processes. In doing so we consider the assumptions that underpin (and emerge from) this legislation. We also consider some related materials, such as the explanatory memoranda that accompany the Acts and what are called the minister's second reading speeches introducing the relevant bills into parliament. ${ }^{3}$ Crucially, these ancillary documents can in certain circumstances have legal force. Where there is ambiguity about the meaning of a law, courts have the ability to look 'behind' the specific wording of the legislation with a view to establishing the intention of the legislators who passed the Act. ${ }^{4}$ In what follows, we argue that much can be gained by analysing statutory instruments and relevant accompanying documents in this way, especially as they offer insights into how governments understand, make and remake the 'nature' and 'effects' of addiction in particular contexts. We also highlight a number of tensions and inconsistencies between the Acts, raising questions about the role of the law in the production and management of addiction as 'multiple' (Mol 2002). Although the focus of this paper is upon Australian law, we argue that our findings regarding the capacity of the law to enact multiple, overlapping and inconsistent ontologies of addiction is a phenomenon likely to be repeated elsewhere, and one that warrants considerably more analysis.

\section{ADDICTION IN THE LAW}

There are a number of legal areas in which substance use and/or 'addiction' figure in Australia. These include:

\footnotetext{
3 All legislation is accompanied by an 'explanatory memorandum' detailing the intended meaning and effect of the act. The 'Second reading speech' is a (typically more lengthy) statement read into parliamentary record about the nature, purpose and intended effect of the bill. The speech precedes parliamentary debate about the legislation. ${ }^{4}$ In Victoria, see, for example, Section 35 of the Interpretation of Legislation Act 1984.
} 
- Personal Injury Law: First, 'addiction' may figure in tort law, as in tobacco litigation where the acquisition of lung cancer and 'addiction' might be alleged. ${ }^{5}$ Alternatively, addiction may figure as a feature or causal component of an injury (depending on one's interpretation), such as an asbestos-related lung cancer. ${ }^{6}$ In civil claims, a plaintiff may also allege that they have developed an addiction - to painkiller medication, for instance - as a direct result of an accident, thus seeking compensation to cover the costs of dependence. ${ }^{7}$ Addiction and substance use may also be raised against a plaintiff in a personal injury lawsuit, as an instance of what is known as contributory negligence or as a defence to a civil negligence claim (under the legal principle of volenti non fit injuria, or voluntary assumption of risk). So, for example, it might be alleged that a person who falls over and sustains an injury as a result of someone else's negligence was in part affected by their substance use or 'addiction';

- Crimes Compensation: Under Australian law, individuals may bring an application for compensation if they are the victim of certain kinds of crimes. ${ }^{9}$ Under some legislation, however, the tribunal or court hearing the application must take into account the victim's past, character, behaviour, attitudes and other factors in determining whether or not they should be compensated, including conduct of the applicant at the time of the crime. ${ }^{10}$ In practice, even where it is established that a crime has occurred, a victim may be denied compensation because of their past substance use or 'addiction' (see Seear and Fraser, in

\footnotetext{
${ }^{5}$ A high-profile example of this is the Australian case of McCabe v British American Tobacco Australia Services Limited [2002] VSC 73, later overturned on appeal in British American Tobacco Australia Services Limited v Cowell (as representing the estate of Rolah Ann McCabe, deceased) [2002] VSCA 1.

${ }^{6}$ See, for example, Amaca Pty Ltd v Ellis; The State of South Australia v Ellis; Millennium Inorganic Chemicals Ltd v Ellis [2010] HCA 5.

${ }^{7}$ For an example, see Askew v Kidd [2008] WADC 142.

${ }^{8}$ For a discussion, see, for example, South Tweed Heads Rugby League Football Club Limited v Cole \& Anor [2002] NSWCA 205; and Connell v Sund \& Anor [2004] VSCA 228.

9 The relevant victims of crime legislation includes the Victims of Crime Assistance Act 1996 (Vic), the Criminal Injuries Compensation Act 2003 (WA) and the Victims of Crime Act 1994 (ACT).

${ }^{10}$ See, for example, section 54 of the Victims of Crime Assistance Act (Vic), which requires the Court to consider the 'the character, behaviour (including past criminal activity and the number and nature of any findings of guilt or convictions) or attitude of the applicant at any time' when deciding whether or not to compensate the victim.
} 
press). As in other areas of the law, it may also be asserted that their 'addiction' raises questions about the victim's credibility as a witness;

- Family Law and/ or Child Protection: Under both family and child protection laws, substance use and/or addiction may emerge as possible 'risk factors' for the safety and welfare of children. ${ }^{11}$ There are a range of possibilities here, but typically children of individuals adjudged to have a substance 'dependence' or 'addiction' may be temporarily or permanently removed from their care and/or placed into a foster home, be denied the opportunity to live with an 'addicted' family member, or have visitation with their 'addicted' family member reduced or subjected to limitations. ${ }^{12}$ Those limitations may include the requirement for contact between a parent and child to be supervised (either by a family member or relevant person, or within a supervised contact facility, where contact is monitored, for example, by social workers). It is also common for drug testing to be undertaken as a condition of continued contact where substance use or 'addiction' is a perceived problem;

- Medical Care: Addiction can be relevant to one's right to receive medical care under Australian law in a variety of ways. In the state of Victoria, for instance, an individual or couple seeking to undergo in vitro fertilization (IVF) treatment must first consent to both a criminal record and child protection check. ${ }^{13}$ If a child has previously been removed from the care of the prospective IVF recipients (as in the case of a drug use or addiction-related intervention), there is a presumption that IVF should not be provided. Patients denied IVF treatment must then go through a review or appeals process demonstrating why they should be entitled to receive IVF;

\footnotetext{
${ }^{11}$ In Australia, the Commonwealth Family Law Act 1975 is the primary law dealing with children's residence and contact issues. Under Section 60CA of the Act, the best interests of the children are paramount. Child protection is governed by the states and territories under separate legislation such as the Children and Young Persons (Care and Protection) Act 1998 (NSW), the Children's Protection Act 1993 (SA), the Children, Youth and Families Act 2005 (Vic) and Child Protection Act 1999 (Qld).

12 See, for example, sections 262 and 281 of the Children, Youth and Families Act 2005 (Vic).

13 These issues are dealt with under Section 12 of the Assisted Reproductive Treatment Act 2008.
} 
- Detention and treatment orders: Perhaps best described as public health legislation, mandatory detention and treatment orders are available in many Australian jurisdictions. ${ }^{14}$ These orders allow for individuals with a 'severe dependence' or addiction to be detained in an addiction treatment program. Although we acknowledge that mandated treatment might be conceptualised as quasi-criminal legislation (given the possibility for coercion or force, and the curtailment of the subject's rights), this legislation is not formally characterised as such in Australia. Instead, it has an explicitly public health focus and has been formulated separately to criminal statutes. Arguably, many 'non-criminal laws' have punitive dimensions or effects, quite regardless of the way those laws are defined or understood. The differences between the purported focus and material 'effects' of legal approaches to addiction and drug use are in fact one of our central avenues of inquiry in this research.;

- Guardianship and administration: Under legislation in most Australian states and territories, applications can be made for a guardianship order on the basis that the 'affected' or 'impaired' person is unable to make decisions for her or himself. ${ }^{15}$ Where such an order is made, the individual granted guardianship of the affected person's affairs has the power to make a range of decisions on behalf of or in respect of the addict and is expected to act in the best interests of the person who is subject to the guardianship order. Here, addiction may be deployed as grounds for such an $\operatorname{order}^{16}$;

- Contract Law: The law of contract and/or equity may require a contract or transaction between two parties to be set aside if there is evidence that one party to the contract has a severe substance use problem, dependency or addiction. Here, addiction may be relevant because of a concern that substance use affected that individual's ability to

\footnotetext{
${ }^{14}$ These matters will be discussed more fully in what follows, but legislation dealing with these issues includes the Severe Substance Dependence Treatment Act 2010 (Vic) and the Drug and Alcobol Treatment Act 2007 (NSW).

15 The relevant legislation includes the Guardianship and Administration Act 2000 (Qld), the Guardianship and Administration Act 1995 (Tas), and the Guardianship and Administration Act 1993 (SA).

${ }^{16}$ For examples, see DQE (No.3) [2008] NSWGT 16 and also HGS [2012] NSWGT 28.
} 
consent to the contract, or because it resulted in an unequal relationship or power imbalance between the parties such that it would be unjust to allow the contract to proceed. The legal doctrines of undue influence and unconscionable conduct are relevant here, and can sometimes be relied upon by an 'addict' to void the contract ${ }^{17}$;

- Discrimination Law: Persons with an addiction or who are receiving medical treatment for that addiction (such as methadone maintenance treatment) may be discriminated against if their condition falls within statutory definitions of disability, disease, disorder or illness. ${ }^{18}$ This raises questions about how addiction is understood and constituted under anti-discrimination law, and the meaning and significance of producing addiction as a disease or disability;

- Refugee Law: Like many other countries, Australia is a signatory to international treaties regarding the protection of persecuted persons. ${ }^{19}$ Our international obligations have been adopted into Australian law, with a comprehensive system for assessing applications from individuals seeking asylum. An appeals system is also in place. ${ }^{20}$ Individuals may apply for asylum on the basis that they are persecuted in their home country. One set of grounds for asylum involves the prospect of persecution in the home country as a result of injecting drug use or being a drug 'addict'. Also, where the individual seeking asylum is HIV or hepatitis C positive (and infection is linked to the 'addiction'), the applicant may assert persecution and should be granted refuge. Here, a decision must be made about

\footnotetext{
${ }^{17}$ There is a substantial body of case law dealing with unconscionable conduct and undue influence Australia, but a key case is that of Blomley $v$ Ryan (1956) 99 CLR 362. More recently, the High Court of Australia explored questions around gambling addiction and unconscionable conduct in Kakavas v Crown Melbourne Ltd [2013] HCA 25.

18 These matters are dealt with in more detail later in this paper, but relevant legislation includes the Disability Discrimination Act 1992 (Cth), the Anti-Discrimination Act 1977 (NSW), the Equal Opportunity Act 1995 (Vic) and the Anti-Discrimination Act 1991 (Qld).

${ }^{19}$ The main document of relevance is the United Nations Convention Relating to the Status of Refugees (1951).

20 The relevant legislation is the Migration Act 1958 (Cth).
} 
whether or not an 'addiction' actually exists and whether this is sufficient grounds for asylum under the relevant legislation ${ }^{21}$;

- Social Security Law: Australia has a state-sponsored welfare system with benefits available to qualifying individuals who are unemployed and/or disabled. ${ }^{22}$ Individuals with an addiction may qualify for a disability support pension based on an examination of their impairment and capacity under established regulations. ${ }^{23}$.

As these examples show, issues of addiction apply to many different areas of legislation well beyond criminal contexts. In some cases it figures as the central focus of legislation - as with mandatory treatment - and in others as a component of legislation with a different focus. Addiction may also feature in common law and the law of equity. Those tasked with making decisions about whether an 'addiction' exists vary; they are sometimes situated in the executive (as with decisions about welfare payments), or at an appeal level. The status of those presiding over cases where addiction may figure also vary: sometimes it is a magistrate or judge with tenure, other times a member of a review board or tribunal without tenure. Our aim here is not to draw any firm conclusions about the implications of this distribution of addiction across so many different legal realms. Further research into the shared and different approaches at work, and the various assumptions and judgments on which these rely, is required before this is possible. Instead our aim is to draw attention to a neglected but important domain in which addiction is constituted and bears on individual access to resources and justice. In doing so, we raise key questions about how addiction fares across these settings as a result of beliefs held among legal professionals and formalised within legal processes about the properties of different

\footnotetext{
${ }^{21}$ For an example case where some of these issues were considered, see 0907840 [2010] RRTA 176.

22 The principal piece of relevant legislation is the Commonwealth Social Security Act 1991.

${ }^{23}$ The distinction is important for several reasons. If a person is assessed as being eligible for a disability support pension, she or he has fewer responsibilities under the relevant legislation (such as the obligation to report to the relevant department regularly, or to actively look for work in order to receive benefits). As of the date of this article, the disability support pension is set at a higher remuneration rate than the general unemployment benefit. For an example of a case where assessment of the nature and level of impairment was in issue, see Quinn and Secretary, Department of Families, Housing, Community Services and Indigenous Affairs [2013] AATA 62.
} 
kinds of substances, the agency and capacity of the 'addict', notions of responsibility and power in relation to addiction, and the various ways that addiction is understood to shape capacity.

\section{ADDICTION AND LEGISLATION}

With these broad questions in mind, we now turn to a more detailed analysis of three specific pieces of Australian legislation in which addiction figures, and consider some of the implications of analysing legislation and ancillary documents in this comparative way. In the next section, we utilise the case study method that was sketched out by Annemarie Mol and John Law in Complexities: Social Studies of Knowledge Practices (2002) and in Law's After Method (2004). According to Mol and Law (2002), traditional social science research tends to be predicated upon realist assumptions of the sort that we outlined earlier, or the belief, in other words, that reality is singular and stable. Traditional research methods both reflect and sustain such realist notions of the world, through implying that there is a singular, stable ontological reality that exists 'out there' for social scientists to independently, objectively observe and capture through the use of appropriate methodological tools, such as the survey. The necessary implication of such approaches is that reality exists 'anterior to ... our reports of it' (Law 2004: 24-5). In contrast, and as we have already explained, Mol and Law argue that ontology is in fact multiple, enacted via material-discursive practices and open to change. What this means is that new, more sensitive and nuanced methods are required in order to attend to the complexity, messiness and multiplicity of realities (Law 2004). Moreover, both Mol and Law argue that methods are one of the means by which realities are made and remade, and that methods participate in the articulation and production of realities rather than the mere observance of them. In Complexities, Mol and Law emphasise the need for new approaches to both research and academic writing that eschew claims to neatness, completeness and order, arguing that such approaches erase the multiplicity and messiness of reality, creating an 'illusion' of order, singularity and stability that is rarely appropriate. Mol and Law (2002) introduce three techniques that researchers might instead 
deploy in order to analyse phenomena without producing a neat or simplistic overview. These three techniques, or methods, are lists, walks and cases. Cases are 'objects of analysis that have epistemological utility without laying claim to representativeness' (Fraser and Seear 2011: 14). Mol and Law (2002: 16) suggest that in contrast with 'the illustration that represents a larger theory, we suggest to treat cases as, again, sensitizing but also unique - as incitement to ask questions about difference and similarity' as well as 'what alters in moving from one place to another'. They go on to say that:

Because they are not, so to speak, representative of something larger (a 'theory'), cases are able to do all kinds of other work. For instance, they may sensitize the reader to events and situations elsewhere that have not been recognized so far and that may well be improbable. They may seduce the reader into continuing to read, to ask what is going to come next. They may suggest ways of thinking about and tackling other specificities, not because they are 'generally applicable' but because they may be transferable, translatable ... They may act as an irritant, destabilizing expectations ... Or they may work allegorically, which means that they may tell not just about what they are manifestly telling but also about something else, something that may be hard to tell directly. (Mol and Law 2002: 15)

In what follows, then, we treat Australian legislation as a 'case' designed to sensitise readers to the various means by which the law participates in the production of addiction as ontologically multiple. In our examination of these laws, we ask the following questions:

- How does addiction figure in the legislation?

- How is the 'problem' defined and what criteria are cited in order to provide a definition or diagnosis?

- How is the agency and subjectivity of the addict enacted? 
- How is the role of the substance enacted?

- Are there areas of uncertainty, tensions or non-coherence? And what is the significance of these?

In asking such questions, following Mol and Law (2002), we aim to destabilise expectations regarding both the ontology of addiction and the role of the law in making and remaking addiction realities. We aim to also encourage some consideration of other places and spaces where similar processes might be unfolding. These are matters to which we shall return later in our conclusion.

\section{The Severe Substance Dependence Treatment Act 2010}

In 2009, the Victorian Labor government introduced a bill for consideration by the state parliament. The Severe Substance Dependence Treatment Bill had been the subject of extensive consultation and discussion over at least five years, and was formally brought into law in 2010 (we shall refer to the legislation hereafter as SSDTA). In essence, the stated aim of the legislation was: 'to provide for the detention and treatment of persons with severe substance dependence' (Severe Substance Dependence Treatment Bill 2009, Clause 1). Under the proposed legislation, any person over the age of 18 could bring an application to the Victorian Magistrates' Court seeking an order to detain (using force, if necessary) and treat any person with 'severe substance dependence'. The proposed bill was complex and it is beyond the scope of this paper to provide a complete overview of it. For present purposes it is sufficient to note that it proposed to introduce a new mechanism for considering applications for the detention and treatment of individuals with severe substance dependence, and provided a series of safeguards to ensure that the rights of the affected person were protected.

The language of addiction is not used within the legislation. Instead, the focus is on 'severe substance dependence', a concept defined in Section 5 of the Act. That Section reads as follows: 
For the purposes of this Act, a person has a severe substance dependence if-

(a) the person has a tolerance to a substance; and

(b) the person shows withdrawal symptoms when the person stops using, or reduces the level of use of, the substance; and

(c) the person is incapable of making decisions about his or her substance use and personal health, welfare and safety due primarily to the person's dependence on the substance.

Under the legislation a person bringing an application before the magistrates' court is required to include a recommendation for detention and treatment from a suitably qualified doctor. In this respect severe substance dependence is squarely positioned as a medical issue. Although the principal Act is largely silent on who qualifies and how the recommendation is to be made, the subsequent Severe Substance Dependence Treatment Regulations 2011 address these issues. Under Section 6 of the regulations, a recommendation for a detention and treatment order may only be made by a qualified psychiatrist, addiction medicine specialist, or a medical practitioner who provides care to patients in police custody at facilities operated by the Victorian police. The regulations also include a sample schedule for the recommendation. This stipulates, in some detail, what information the prescribed medical practitioner is expected to provide. ${ }^{24}$ The practitioner is eligible for a fee for their services in providing the recommendation. Once the recommendation is made, the application for a detention and treatment order is heard by a magistrate. The affected person has the right to appear and be legally represented at the hearing of the application. If an order is made, it is for a finite period (14 days), with a focus on medically-assisted withdrawal.

\footnotetext{
${ }^{24}$ This includes details of the type of substance/s involved, the nature and length of time of the dependence, the basis upon which the practitioner asserts that the affected person is incapable of making decisions primarily due to substance dependence, and so on. The practitioner is also expected to document the basis upon which they believe treatment is necessary and the reasons why they believe no less restrictive means of treatment is reasonably available to them (Schedule 2, Severe Substance Dependence Treatment Regulations 2011).
} 
A detailed analysis of the consultation process leading to the development of the legislation is beyond the scope of this paper, but there are some important factors to note regarding the history and introduction of the bill. Crucially, the legislation proposed by the Victorian government sought to replace an earlier law that also dealt with the detention and treatment of individuals with severe alcohol and drug problems. That earlier law was called the Alcoholics and Drug-dependent Persons Act 1968 (the ADDPA). In the second reading speech made by the minister introducing the proposed new bill to parliament, it was suggested that a new piece of legislation was necessary in order to 'modernise the law', although it was not entirely clear what was meant by modernisation. The minister announced that the SSTDA would provide 'a more compassionate approach' to affected people, along with a new way of approaching the nature and role of treatment. Under the ADDPA, treatment facilities had the capacity to administer coercive medical treatment for a potentially much longer period. Perhaps it was the dual nature of that treatment (as potentially coercive and lengthy) that the minister considered to be outdated. In any event, the SSTDA would usher in a subtle but potentially significant shift in language. No longer referred to as 'alcoholics' and 'drug-dependent persons', the new Act mobilised the language of 'substance dependence', terminology that, according to Kranzler and Li (2008: 93) had 'gained great currency because of its use in the Diagnostic and Statistical Manual of Mental Disorders (DSM) $\cdot{ }^{25}$ In this way, the SSTDA both draws upon and reproduces a disease model of substance dependence. Importantly, however, the Act also introduced the need for 'severity'. While the ancillary materials say nothing about why the term is included or what it means, we can say a few things about how it constitutes the idea of 'substance dependence'. One implication is that it produces a continum of substance dependence such that, paradoxically, the Act simultaneously posits a pre-existing state of being ('severe substance dependence') and

\footnotetext{
25 See, for example, the DSM-IV-TR (American Psychiatric Association 2000).
} 
endeavours to constitute it, by defining certain attributes and behaviours (those listed in section 5) as 'severe' rather than minor or moderate. ${ }^{26}$

Beyond the use of the expression 'substance dependence', the legislation, explanatory memorandum or second reading speech contain virtually no information to indicate what theory (or theories) of addiction underpinned the construction of the Act. This is an important point given that there are multiple theories about what addiction 'is' and how it 'works' (West 2001, 2006a, 2006b), and a recognition that important differences in effects exist between substances, especially in relation to the key markers of severe dependence cited in the Act - tolerance and withdrawal. Methamphetamine is widely considered, for example, to be highly addictive (and as such is probably considered a very pertinent substance for the Act), yet it is generally seen in medical and public health circles to be extremely unlikely to produce a withdrawal syndrome (Weaver 2010). In the absence of further information, we are left only with what appears within the Act itself, and those documents, described earlier, that can be used to assist our interpretation of it. This raises the question: how does the specific model of addiction constituted within the Act sit with other theories about addiction and agency in other Acts and in wider expert knowledges? What is the role of interpretation among the legal functionaries tasked with implementing the Acts and their assumptions? How, moreover, do court-mandated forms of treatment mesh with the range of extant approaches to addiction treatment, especially since, overall, treatment is recognised within public health and medical circles to be of modest effectiveness (Ritter and Lintzeris 2004)? These questions are important for a number of reasons including, as mentioned, treatment outcomes. Is there an assumption under the SSTDA that

\footnotetext{
${ }^{26}$ This interpretation is supported by the minister's second reading speech, where a distinction was drawn between severe substance dependence and other kinds of substance use and/or problems associated with drug and alcohol use: 'The bill does not target the issue of alcohol-fuelled violence or street drinking. Neither is the bill concerned with binge drinkers or those who become aggressive when under the influence of alcohol. These are all significant community issues that are being addressed by the Victorian Alcohol Action Plan, but there is no research evidence that such behaviours will respond to the involuntary treatment to be provided under the bill. Neither does the bill target people who use substances at dangerous levels over a long period of time'.
} 
positive treatment outcomes for severely dependent patients are less reliant upon the beliefs and wishes of the affected individual than they are for other patients? If so, why? And what might this tell us about how the agency of the 'addict' is understood in this context?

Other examples of the kinds of questions raised by the Act also bear consideration. Looking at both the legislation and the minister's second reading speech, the legislation appears, for example, to produce a potentially contradictory set of notions about the role of volition in the dependent person's life. On the one hand, severely dependent persons are understood to be incapable of making decisions about their substance use, health, welfare and safety primarily because of their dependence. In this sense, substances are understood to have the potential to seriously curtail the agency of the dependent person such that intervention is warranted. The effects of substance use on agency are also understood to be objectively measurable (usually within a single consultation with a prescribed practitioner) and treatment is, according to the minister's second reading speech, the means by which capacity or agency is 'enhanced' (Minister Andrews, second reading speech). In spite of this, the speech also clearly envisages a collaborative relationship between a person who is the subject of the order and the treatment facility, in ways that appear to contradict the volition test that is central to the definition of 'severe substance dependence' upon which the entire Act turns. Similarly, we must consider what it means that the affected person is permitted - but not required - to be legally represented at the hearing of the application, especially since this raises the possibility that they might elect to represent themselves. While we are not suggesting that an individual facing an application under the Act is necessarily incapable of representing her or himself, we do find it difficult to reconcile the implication that individuals might be thought to have the capacity to appear before a magistrate in respect of a matter with potentially serious human rights implications when questions about their capacity are simultaneously at stake; indeed, those questions are the very basis for the application itself. In highlighting these issues, our intention is not to produce a comprehensive 
account of this legislation, nor of the contradictions or tensions that may underpin it. Instead, these few examples are given to demonstrate that even a single piece of legislation purporting to address addiction (here 'substance dependence') may throw up many questions about its object, and about how the agency of addicted (or 'dependent') individuals can be understood. A comparison with other legislation, enacted both within and outside the same jurisdiction in relation to a single area of the law provides further evidence of this phenomenon.

2 and 3. Disability discrimination: State versus federal law

The second and third examples of the operation of addiction within non-criminal legal processes are two pieces of Australian legislation dealing with disability discrimination. The first, the Disability Discrimination Act 1992 (DDA), is a federal (Commonwealth) law, whereas the second, the Anti-Discrimination Act 1977 (ADA), is a state law, specific to New South Wales. These pieces of legislation were the result of events that occurred at a club on the north coast of NSW: the Coffs Harbour and District Ex-Service Men and Women's Memorial Club. Between 1994 and 1996, a local club member by the name of Wayne Marsden experienced a number of encounters with club officials regarding his personal presentation and behaviour. Wayne had been a heroin user as a teenager but later entered into a methadone program. He was unemployed and living with hepatitis C. Staff members accused him of intoxication, when, according to Wayne, he was instead unwell or suffering from side effects of methadone maintenance treatment (Gibson 2009). When he was later found to be consuming alcohol at the club, the board expelled him as a member. Wayne lodged a complaint with the Human Rights and Equal Opportunity Commission (HREOC) on the basis that he had been discriminated against because of his 'disability' (a practice prohibited under the DDA). He asserted that he was dependent on methadone and suffered from hepatitis $\mathrm{C}$ and that either or both of these constituted a disability within the meaning of the Act. Section 4 of the DDA defines disability as including a 'disorder, illness or disease that affects a person's thought processes, perception of reality, emotions or 
judgment or that results in disturbed behaviour'. The HREOC rejected Wayne's complaint, finding that opioid dependence 'does not constitute a disability as defined'. Wayne sought redress from the Australian Federal Court, the body that reviews decisions of the HREOC. Although the court did not decide whether discrimination had occurred, it found that the HREOC had made procedural errors in coming to its decision. The question, therefore, of whether methadone dependence constitutes a disability was left open. The case was then settled confidentially and Wayne was allowed to return to the club (Gibson 2009).

A detailed summary of what happened next appears in Frances Gibson's analysis of the case (2009). After extensive media coverage and criticism of the Federal Court decision, the NSW government announced a review of state legislation pertaining to disability, with a view to ensuring that 'addicts' did not use their disability as grounds for pursuing compensation or other benefits. Although the Marsden case had been based on federal legislation, the NSW AntiDiscrimination Act 1977 (ADD) defined 'disability' in near-identical terms. A bill was introduced into parliament proposing that drug 'addiction' be specifically excluded from the definition of disability under the Act, for the purposes of employment law. ${ }^{27}$ The legislation was passed, so that the relevant parts of the specific exclusion read:

(2) Nothing in [the provisions pertaining to discrimination in employment] renders unlawful discrimination against a person on the ground of disability if:

(a) the disability relates to the person's addiction to a prohibited drug, and (b) the person is actually addicted to a prohibited drug at the time of the discrimination.

\footnotetext{
${ }^{27}$ This mirrors practice in the UK, where the Equality Act 2010 specifically excludes individuals with an alcohol or other drug addiction (Flacks 2012). Importantly, as Flacks (2012) points out, this exclusion is at odds with the two most widely-recognised systems for classifying mental health disorders at the time: the DSM-IV, mentioned earlier, and the International Classification of Diseases (or ICD), issued by the World Health Organisation (2007).
} 
(3) However, nothing in this section makes it lawful to discriminate against a person on the ground of the person having hepatitis C, HIV infection or any medical condition other than addiction to a prohibited drug. ${ }^{28}$

The minister's second reading speech for this bill described the intention of the bill as ensuring that anti-discrimination laws would not be 'used in an unintended manner'. Referring directly to the Wayne Marsden case, the minister raised concerns about the 'risk' associated with understanding drug addiction as a disability under the Act, pointing to the 'concerns' of employers. The bill would also draw a distinction between 'actual' and 'perceived' addiction, such that 'employers cannot discriminate against persons who have overcome their addictions or against persons who are not in fact addicts'. Crucially, 'addiction' is not defined anywhere in the Act, so that it is unclear how an addict is 'in fact' constituted. In 2003, the Federal Government proposed similar legislation, so that the Federal DDA would specifically exclude substance 'addiction' from the definition of 'disability'. Although this bill was drafted and introduced into parliament, the legislation was never passed and eventually lapsed. We are left, then, with a curious scenario in which the principal piece of anti-discrimination legislation at the Commonwealth level leaves open the possibility that addiction constitutes a form of 'disability' that can be mobilised in certain circumstances by an aggrieved individual, but at the state level, one form of addiction (AOD) is specifically excluded. Putting to one side practical questions about accessing relief under either or both of the Acts, and about conflicting laws, these examples demonstrate, we argue, the possibility of variations within a single legal realm in definitions of what addiction 'is', whether or not it is a disease or disability, the agency and capacity of individuals adjudged to be living with an addiction, and their rights and responsibilities under Australian law. In excluding only drug addiction from the definition of

\footnotetext{
28 Methadone and buprenorphine were specifically excluded from the list of prohibited drugs, so that a person may still be discriminated against under the Act based on a methadone or buprenorphine dependence.
} 
'disability', the ADD also arguably implies that other forms of addiction might be understood as a disease, disability, or both. ${ }^{29}$ In this way, our comparison of the DDA and ADD demonstrates at least three things. First, the ontological, medical and legal status of addiction under Australian anti-discrimination law is multiple, inconsistent and potentially contradictory. Secondly, the law (at least within the state of NSW) produces different kinds of addictions, and in so doing produces some forms of addiction as more valid and acceptable than others, insofar as the availability of legal relief can be taken to be a marker of this. Finally, addiction is constituted under anti-discrimination law as both a recognised disability, and a moral failing or moral culpability, to the extent that at least one law explicitly permits discrimination on the basis of drug addiction. In sum, the status of addiction in Australian law is, it seems from our examples, changeable and multiple. Often poorly defined, it varies in standing from invalid transgression warranting punishment to valid mitigation likely to reduce or preclude punishment.

\section{CONCLUSION}

In this paper we have demonstrated that addiction figures across many different legal realms, including a range of non-criminal settings. Our overview of law and practice in Australia documents substantial case law and legislation dealing with issues around addiction and finds subtle but potentially significant variations between these in the meaning and implications of addiction. Our point, following Joh (2009), is that it is not possible to speak of a single or consistent legal response to alcohol and other drug issues, including addiction, whether within a single jurisdiction involving pieces of legislation enacted at the same point in time, or within a broader area where more than one legislative instrument may apply. The terminology and criteria

\footnotetext{
${ }^{29}$ Although this would appear to be a logical conclusion based on the clear language of the amending section (and the second reading speech itself), it is also arguably supported by a legal doctrine known as noscitur a sociis. The noscitur maxim is a principle of statutory construction whereby the construction of a word or words within a statutory instrument is to be construed by reference to other words and phrases in the Act (i.e. through the broader context of the legislation). So, the absence of an exclusion for other types of addiction, and the specific reference to addiction to a prohibited drug likely reinforces the notion that other forms of addiction can be forms of disability under the Act.
} 
for determining 'addiction' regularly differ, often with little or no explanation as to why the terms and criteria have been chosen, and the processes associated with how an 'addiction' is established may also be conflicting or vague. Also, forms of addiction may be constituted differently, producing and reproducing subtle variations in how addictions 'work', and the agency and subjectivity of different 'kinds' of addicts. These differences open up a range of issues, some of which we have touched upon here. Where different language and criteria are used, legislation may be interpreted differently, so that case law and legal practice may develop along divergent trajectories. This can have major implications for the rights and responsibilities of people living in different legal jurisdictions - a point valid well beyond the present context of Australian law. Indeed, it is unlikely that Australia is alone in its complex and multilayered legal engagements with addiction. For the reasons we outlined earlier in this paper, and in the tradition of case methods outlined by Mol and Law (2002), we would encourage more and more comparative analyses of these legal processes internationally, and more work that examines the implications of these approaches for individuals subjected to them. In relation to the latter, we know far too little about the role of different (especially non-criminal) legal realms in the production, maintenance and/or destabilisation of the stigmatisation and marginalisation of addicts, or how these processes otherwise impact upon affected individuals. The lived experiences of individual 'addicts' may also be complicated where they are caught up in more than one legal realm where ideas about addiction, agency and responsibility are handled differently, or where addiction is constituted multiply. In all these ways, the identification and management of addictions across the legal spectrum has potentially major public health implications, with the prospect of serious repercussions for individuals who use substances and/or are framed as 'addicts', or for whom treatment is prescribed. On the basis of this research, we argue that there is a need for much more work on the place of addiction in non-criminal realms and the possible implications and 'effects' of these configurations. 


\section{REFERENCES}

American Psychiatric Association. (2000). Diagnostic and Statistical Manual of Mental Disorders, Fourth Edition Text Revision (DSM-IV-TR). Washington, DC: American Psychiatric Association.

Brook, H. \& Stringer, R. (2005). Users, using, used: A beginner's guide to deconstructing drugs discourse. International Journal of Drug Policy. 16(5), 316-325.

Burke, A. \& Clapp, J. (1997). Ideology and social work practice in substance abuse settings. Social Work. 42, 552-564.

Burns, S. \& Peyrot, M. (2003). Tough love: Nurturing and coercing responsibility and recovery in California drug courts. Social Problems, 50(3): 416-438.

Clancey, G. \& Howard, J. (2006). Diversion and criminal justice drug treatment: Mechanism of emancipation or social control? Drug and Alcohol Review, 25: 377-385.

Courtwright, D. (2010). The NIDA brain disease paradigm: History, resistance and spinoffs. BioSocieties, 5(1), 137-147.

Deleuze, G. (1994). Difference and Repetition. London: Athlone Press.

Fitzgerald, J. (2008). Drug diversion: An intersection between law enforcement and public health approaches to the control of illicit drug use. In D. Moore \& P. Dietze (Eds.) Drugs and Public Health (pp.103-113). Oxford and London: Oxford University Press.

Flacks, S. (2012). Deviant Disabilities: The exclusion of drug and alcohol addiction from the Equality Act 2010. Social and Legal Studies. 21(3), 395-412.

Fox, K. (1999). Ideological implications of addiction: Theories and Treatment. Deviant Behavior: An Interdisciplinary Journal, 20, 209-232.

Fraser, S. (2013). Junk: Overeating and obesity and the neuroscience of addiction. Addiction Research and Theory. doi: 10.3109/16066359.2012.749868

Fraser, S. \& Seear, K. (2011). Making disease, making citizens: The politics of hepatitis C. Ashgate: Aldershot. 
Fraser, S. \& valentine, k. (2008) Substance and substitution: Methadone subjects in liberal societies, Palgrave: Basingstoke.

Gibson, F. (2009). Drugs, discrimination and disability. Journal of Law and Medicine. Volume 17, 400-411.

Gowan, T. \& Whetstone, S. (2012). Making the criminal addict: Subjectivity and social control in a strong-arm rehab. Punishment and Society, 14(1): 69-93.

Karasaki, M., Fraser, S., Moore, D. \& Dietze, P. (2013). The place of volition in addiction: Differing approaches and their implications for policy and service provision. Drug and Alcohol Review. 32 (2), 195-204.

Keane, H. (2002). What's Wrong with Addiction? Melbourne: Melbourne University Press.

Keane, H., Moore, D. \& Fraser, S. (2011). Addiction and dependence: Making realities in the DSM. Addiction, 106(5), 875-877.

Hyman, S. (2005). Addiction: A disease of learning and memory. The American Journal of Psychiatry, 162(8), 1414-1422.

Joh, E. (2009). Imagining the addict: Evaluating social and legal responses to addiction. Utah Law Review. 175, 175-194.

Kelly, J. \& Igelman, A. (2009). Compulsive gambling litigation: Casinos and the duty of care. Gaming Law Review and Economics, Vol. 13, No. 5, 386-403.

Law, J. (2004). After Method: Mess in social science research. London and New York: Routledge.

Levine, H. (1978). The Discovery of Addiction: Changing Conceptions of Habitual Drunkenness in America. Journal of Studies on Alcohol, 39, 143-174.

Marrati, P. (2006). Time and affects: Deleuze on gender and sexual difference. Australian Feminist Studies, 21(51), 313-325.

Miller, N.S. (Ed.) (2010) Principles of Addictions and the law: Applications in forensic, mental health and medical practice. London: Elsevier. 
Mol, A. and Law, J. (2002). Complexities: An introduction, in Complexities: Social Studies of Knolwedge Practices, edited by J. Law \& A. Mol. Durham: Duke University Press, 1-22.

Mol, A. (2002). The Body Multiple: Ontology in Medical Practice. Durham: Duke University Press.

Mol, A. (1999). Ontological politics. A word and some questions, in Actor Network Theory and After, edited by J. Law and J. Hassard. Oxford: Blackwell Publishers, 74-89.

Moore, D. and Fraser, S. (2013). Producing the 'problem' of addiction in drug treatment. Qualitative Health Research, 23, (7), 916 - 923.

Murphy, J. (2012). The continuing expansion of drug courts: Is that all there is? Deviant Behavior, $33,582-588$.

Murphy, J. (2011). Drug court as both a legal and medical authority. Deviant Behavior, 32: 257-291.

Race, K. (2012). Framing Responsibility: HIV, Biomedical Prevention, and the Performativity of the Law. Bioethical Inquiry. 9: 327-338.

Ritter, A. \& Lintzeris, N. (2004). Specialist interventions in treating clients with alcohol and drug problems. In M. Hamilton, T. King, \& A. Ritter (Eds.), Drug use in Australia: Preventing harm (pp. 221-235). South Melbourne: Oxford University Press.

Robinson, T.E. \& Berridge, K.C. (2003). Addiction. Annual Reviews in Psychology, 54, 25-53.

Room, R. (2006). Addiction concepts and international control. The Social History of Alcohol and Drugs. 20, 276-289.

Saldanha, A. 2003. Actor-Network theory and critical sociology. Critical Sociology, Vol. 29, Issue 3, 419-432.

Seddon, T. (2007a). Drugs and freedom. Addiction Research and Theory, 15(4): 333-342.

Seddon, T. (2007b). Coerced drug treatment in the criminal justice system: Conceptual, ethical and criminological issues. Criminology and Criminal Justice, 7(3): 269-286.

Seear, K. \& Fraser, S. In press. The addict as victim: Producing the 'problem' of addiction in Australian victims of crime compensation laws. International Journal of Drug Policy. 
Seear, K. \& Fraser, S. (2010a). Ben Cousins and the 'double life': exploring citizenship and the voluntarity/compulsivity binary through the experiences of a 'drug addicted' elite athlete. Critical Public Health, Vol 20, Issue 4, 439-452.

Seear, K. \& Fraser, S. (2010b). The 'sorry addict': Ben Cousins and the construction of drug use and addiction in elite sport. Health Sociology Review, Vol. 19, Issue 2, 176-191.

Taxman, F. \& Bouffard, J. Substance abuse counselors' treatment philosophy and the content of treatment services provided to offenders in drug court programs. Journal of Substance Abuse Treatment, 25, 75-84.

Treloar, C. \& Holt, M. (2006). Deficit models and divergent philosophies: service providers' perspectives on barriers and incentives to drug treatment. Drugs: Education, prevention and policy. Vol. 13, No. 4, 367-382

Volkow, N. \& Li, T.K. (2004). Drug addiction: the neurobiology of behaviour gone awry. Nature Reviews, 5, 963-970.

Vrecko, S. (2010). 'Civilising technologies' and the control of deviance. BioSocieties, 5(1), 36-51.

Weaver, M. (2010). Medical sequelae of addiction. In D. Brizer \& R. Castaneda (Eds.), Clinical Addiction Psycbiatry (pp. 23-36). Cambridge: Cambridge University Press.

West, R. (2001). Theories of Addiction. Addiction, 96, 3-13.

West. R. (2006a). Theory of Addiction, Blackwell: Oxford.

West, R. (2006b). Towards a comprehensive theory of addiction. Drugs and Alcohol Today, Vol. 6, Issue 1, March, 28-32.

Wild, T.C. (2006). Social control and coercion in addiction treatment: Towards evidence-based policy and practice. Addiction, 101: 40-49.

World Health Organisation. (2007). ICD-10: The ICD-10 Classification of Mental and Behavioural Disorders: Clinical Descriptions and Diagnostic Guidelines. Geneva: World Health Organisation. 